\title{
Employee Engagement: An Actual Theme, in a Permanent Evolution
}

\author{
Radu MARIN \\ National University of Political Studies and Public Administration, Bucharest, Romania, \\ radumarin62@gmail.com
}

Received date:23 March 2021; Accepted date:5 September 2021; Published date: 2 November 2021

Academic Editor: Doina I. Popescu

Copyright (C 2021. Radu MARIN. Distributed under Creative Commons Attribution 4.0 International CC-BY 4.0

\begin{abstract}
Modern companies are well aware of the fact that employee engagement can contribute, in a decisive manner, to the company's competitiveness and performance. This paper's purpose is to analyse how employees' engagement was defined over time in the literature, in order to highlight the methods by which employees' engagement can be determined, to identify the factors that lead to employee engagement, and to highlight how a successful employee engagement program can be developed. The paper will try to demonstrate that engaged employees are more competitive and efficient, which leads to the success of the organizations. The paper also aims to highlight the problems that may arise in the process of determining and developing employees' engagement programs, and tries to provide answers to the questions and difficulties related to employee engagement that organizations can face. This study is considered to be topical, given the economic difficulties that companies are facing now as a result of the challenges generated by the COVID-19 pandemic, which has led both to the emergence of a new economic crisis and to an unprecedented change in the way employees operate within organizations, and the increasing number of employees carrying out activities based on teleworking.
\end{abstract}

Keywords: Employee Engagement, Organizations Outcomes, Job Satisfaction

Jel Classification: E24, J24, L25,

\section{Introduction}

In the fall of 2008, the UK Secretary of State for Business, Innovation and Skills requested a study in order to thoroughly analyze employee engagement and how it could positively influence employee involvement in companies and organizations. Moreover, the following spring, the Secretary of State set up a meeting with David MacLeod and Nita Clarke, the people chosen to carry out the study, asking them to investigate whether a broader application of employee engagement would produce a beneficial effect in terms of the performance and competitiveness for UK companies (MacLeod, D. and Clarke, N., 2009, 3). The

Cite this Article as: Radu MARIN (2021)," Employee Engagement: An Actual Theme, in a Permanent Evolution", Journal of Human Resources Management Research, Vol. 2021 (2021), Article ID 796417, DOI: $10.5171 / 2021.796417$ 
study was aimed to act as a support for British businesses, as the economic crisis began to develop and was expected to start showing effects. This study was considered to be useful because a 2005 Gallup similar study revealed a fact related to the low percentage of engaged employees and the negative effects this can have on organizations.

In this study, "At Work, Feeling Good Matters", Jerry Krueger and Emily Killham presented the findings obtained by Gallup researchers, based on a survey conducted in U. S. organizations as follows: $27 \%$ of respondents were engaged, while 59\% were unengaged and $14 \%$ were actively unengaged. Moreover, the study showed that the decrease in productivity generated by the $14 \%$ of actively unengaged workers cost the U. S. economy between $\$ 292$ billion and $\$ 350$ billion in the first quarter of 2005 alone. MacLeod, D. and Clarke, N. $(2009,66)$ identified the following obstacles that may arise when organizations intend to implement employee engagement growth programs: there are managers who do not fully understand the concept of engagement, are not concerned or are unaware of the importance of increasing employee engagement in terms of the impact this approach has on the organization's performance; there are managers who, although they understand both the concept and the importance of employee engagement, either do not know how to approach and implement it, or they do not communicate with other managers on this topic, thus preventing the development of an unitary program meant to increase employee engagement at the organizational level; even among managers who are concerned with increasing the level of employee engagement, there are certain managers who either underestimate its importance in terms of the results of the organization or use the wrong tools to identify it.

Over time, the issue of employee engagement has become so important within organizations that in 2015, Josh Bersin, in his article published on Deloitte's website, "Becoming irresistible: A new model for employee engagement", found that the problem of employee engagement came second in terms of organizations' concerns, right after the construction of global leadership. However, Josh Bersin presented a sad reality within organizations that only $50 \%$ of those in leadership positions understood how to address this issue, although $90 \%$ of them understood its importance. The author believes that managers need to adopt best practices and understand the concept of engagement in the light of new challenges faced by organizations.

Perhaps this is the reason why, despite the efforts of organizations, the level of employee engagement has very slowly increased over time. In the article "Employee Engagement Continues Historic Rise Amid Coronavirus", published on the Gallup website in May 2020, Jim Harter found that between 2000 and 2020, the percentage of engaged employees in US increased very slowly (from $26 \%$ to $38 \%$ ), while the percentage of actively disengaged employees decreased very slowly (from $18 \%$ to $14 \%$ ). In addition, an extra negative factor was represented by the $49 \%$ of employees who continued to be disengaged. The author also pointed out that growth from $35 \%$ in 2019 to $38 \%$, represented a historical one, never before achieved in the American economy. It is considered that there were three elements that led to this situation, the first of which being related to the response of the organizations, the second is related to the conditions under which the study was conducted, and the third is directly related to the perception of the employees.

The response of the organizations was accelerated after the outbreak of the COVID19 pandemic, with an increased level of communication in order to prepare employees to work under the new conditions, and managers constantly communicated to the employees the latest outcomes related to the economic evolution and pandemic. Given the timing of the study (end of April and early May), as well as the sharp increase in the unemployment rate in the American economy, it is very likely that among the first employees fired, were those with a lower level of engagement, and the 
Gallup study included only a small cluster of them in the sample. Also related to the problem of increased unemployment, is motivating those remaining in organizations - in the current situation - to have a more appreciative attitude towards their job, and their answers to engagement related questions could have been artificially more favorable.

The fact that trying to conduct a study in times of crisis with the possibility to reach atypical results can also be concluded by analysing the studies published by Gallup in July 2020, "Historic Drop in Employment Follows Record Rise" and "U. S. Employee Engagement Hits New High after Historic Drop" and in February 2021, "U. S. Employment Engagement Rise Following Wild 2020", also authored by Jim Harter. The percentages representing the engaged employees ranged from 37\% (survey conducted in March 2020), 38\% (survey carried out at the end of April 2020 and beginning of May 2020), 31\% (survey carried out at the beginning of June 2020), $40 \%$ (survey carried out at the end of June 2020 and beginning of July 2020) and 39\% (survey carried out in January 2021). It is also worth noting that the percentage of engaged employees was achieved due to the disengaged ones, as the percentage of actively disengaged employees remained at $14 \%$, after an insignificant decrease of one percent in the survey conducted at the end of June 2020 and the beginning of July 2020 .

Analyzing Gallup's studies throughout 2020 , it can be concluded that surveys carried out during periods of crisis can provide inconclusive results regarding the trend in the level of employee engagement. However, this article is considered very actual, due to the fact that the Gallup study published in May 2020, specified above, finds a closer relationship between employee engagement and performance of the organization's results (productivity, profitability, customer perception, employee retention) in crisis times in comparison to non-crisis ones.

\section{Research Outline}

The author of this paper has aimed to fulfill an analytical review of the studies and articles published in the last three decades in order to identify the way in which the definition of employee engagement has developed during this period.

Another goal of the paper was to identify the various types of employees (engaged, notengaged, actively disengaged) working within an organization and the way in which each kind of employee level of engagement could influence the outputs of the organizations.

The third objective of the study was to highlight the incentives that could be implemented by the organizations in order to increase the number of the engaged employees.

\section{Findings}

\section{Defining the Term of Employee Engagement}

Although this topic has been studied since the end of the last century in specialized literature and academic literature, and has seen an extensive development in managerial practices this century, the term employee engagement continues to be highly contested. In the first part of this paper, the author will try to offer some of the definitions that can be given to this attitude of the employees.

Although Gallup's studies on this subject began to be carried out as early as in 1985, the term 'employee involvement', as well as the one referring to the lack of employee engagement, were defined for the first time by Kahn, W. A. (1990). It is worth mentioning that the definitions given by Kahn are actually related to personal engagement and lack of personal engagement. The two terms defined the behavior of employees in terms of the extent to which employees are willing to bring in or leave out their personal selves during work role performance. The author defined employee engagement as the utilization of employees' own personalities 
and self characteristics, both of a physical nature, as well as of a cognitive and emotional nature, during work within the organization. In opposition, disengaged employees avoid revealing and using their personalities and personal characteristics during work role performance (Kahn, W. A., 1990, 694).

Rothbard, N. P. (2001, 656-657), based on the conclusions of previous studies, considers engagement in a role as the focus on the role's activities. The author considers engagement to be important for the performance achieved in that role and concludes that it has two important consequences: attention (cognitive availability and the length of time that a person is willing to allocate to think about that role) and absorption (intensity of focus on that role).

Schaufeli, W., Salanova, M., Gonzalez-Roma, V. and Bakker, A. B. (2002, 74-75) defined engagement as a positive, fulfilling, and work-related state of mind that is characterized by three elements: vigor (characterized by high levels of energy and mental resilience while working, the willingness to invest effort in one's work, and persistence even in the face of difficulties.), dedication (characterized by a sense of significance, enthusiasm, inspiration, and pride) and absorption (characterized by being fully concentrated and deeply engrossed in one's work, whereby time passes quickly and one has difficulties in detaching oneself from work). In fact, these three factors were the base of Utrecht Work Engagement Scale, the most used tool today developed with the purpose of measuring employee engagement.

Harter, J. K., Schmidt, F. L. and Hayes, T. L. (2002, 269) believed that employee engagement refers to the individual's involvement and satisfaction as well as enthusiasm for work. The definition is considered to be important because it highlights the liaison between employee engagement and work satisfaction.

Robinson, D., Perryman, S. and Hayday, S. (2004, IX) showed that the Institute for Employment Studies defined employee engagement as a positive attitude of employees towards the organization and its values. The authors considered employee engagement as being a two-way relationship: on the one hand, the organization is responsible for expressing concerns in the sense of obtaining employee engagement, and on the other hand, in response to this attitude, employees can decide on the level of engagement they are willing to offer to the employer.

Saks, A. M. (2006, 602) considers employee engagement as being "a distinct and unique construct that consists of cognitive, emotional, and behavioral components that are associated with individual role performance". However, the author would point out that this definition was recognized only by academic literature, because in the literature addressed to practitioners, employee engagement was often considered as intermerging with other theories, especially with organizational engagement, organizational citizenship behavior and job involvement.

Macey, W. H. and Schneider, B. (2008, 6-13) addressed the meaning of the term 'engagement' by trying to compare it with related theories: satisfaction, commitment, job involvement, psychological empowerment, positive affectivity, and involvement of the self. Regarding the comparison with satisfaction, the author finds that, in practice, many of the measurements made to determine the engagement are very close to those used for the purpose of assessing professional satisfaction. The authors highlight the three faces of engagement: self engagement (a positive image in terms of life and work), state engagement (feelings of energy and absorption) and behavioral engagement (extra-role behaviour) (Macey, W. H. and Schneider, B., 2008, 6-13). In addition, Macey, W. H., Schneider, B., Barbera, K. M. and Young, S. A. $(2009,20)$ clarified that four components were requested in order for an employee to be engaged: urgency, concentration, intensity with which he carries out activities and enthusiasm.

Zigarmi, D., Ammon, K., Houson, D., Witt, D. and Diehl, J. (2009, 310) used the term

Radu MARIN (2021), Journal of Human Resources Management Research, 
'passion for work' instead of the notion of engagement, which they defined as "an individual's persistent, emotionally positive, mean-based, state of wellbeing stemming from reoccurring cognitive and affective appraisals of various job and organizational situations that results in consistent, constructive work intentions and behaviors".

Chalofsky, N. E. $(2010,131)$ adopted the definition of employee engagement provided by Gibbons, J. (2006, 4), who considers that employee engagement requires a high-level of connection that is established between the employee and the organization and that makes him exert a greater and discretionary effort in work.

Shuck, B. and Wollard, K. (2010, 103) identified employee engagement as "the individual cognitive, emotional and behavioural state of an employee directed at the desired organizational results". Moreover, Shuck, B., Reio, T. G. Jr. and Rocco, T. S. $(2011,427)$ considered that the state of employee engagement is thought to be inclusive of long-term emotional involvement. The authors consider that the state of employee engagement is an antecedent to more temporary generalities of employees' sentiments, such as job satisfaction and commitment. M. B., Rocco, T. S. and Albornoz, C. A. (2011, 316) considered engagement, as well as the lack of employee engagement, as holistic experiences, perceived and subsequently interpreted by each person in the light of one' own experience, individual reasoning and opinions. This leads to the authors' conclusion that employee engagement should be considered as an individual state and not as a behavioural model or organizational variable.

Christian, M. S., Garza, A. S. \& Slaughter, J. E. $(2011,95)$, using the title of engagement in work, defined it as "a relatively lasting state of mind regarding the simultaneous investment of personal energies in a job experience or performance".

Shanmugam, P. and Krishnaveni, R. (2012, 190) defined involvement as the level of loyalty manifested in relation to the organization, along with the additional effort made to achieve the company's objectives.

Taking, as a starting point, the definitions previously offered in the specialized literature, Witemeyer, H., Ellen, P. and Straub, D. $(2013,1)$ provided a definition of engagement that contained all the elements of engagement identified in previous studies. Thus, they defined engagement as an attitude towards one's work in one's organization, comprising feelings of vigor, dedication, and absorption; cognitive appraisals of psychological empowerment; and motivation to act, both within role and extra role, in the service of the organization's goals.

Das, S. P. \& Mishra, P. S. (2014, 74-75) considered, based on literature review, that employee engagement is based on four major constructs: personal involvement, burnout engagement, work engagement and mindful engagement.

Ababneh, O. A. A. $(2015,20)$ tried to give a definition of employee engagement that would constitute a corollary of all previous definitions. The author considers employee involvement as "a multidimensional construct that refers to passionate, energetic, enthusiastic, persistent, focused, and emotionally positive individuals who have their personal attributes, along with their cognitive and affective evaluations of job and organizational situations, to direct their task performance towards reaching the organizational objectives".

\section{Identifying employee engagement levels and their impact on the organization}

In the article "At Work, Feeling Good Matters", Jerry Krueger and Emily Killham presented the categories identified in a study published in The Gallup Management Journal, regarding the level of employee engagement. In the article, the authors also presented the definitions of the three categories of employees. Engaged employees are those who have the ability to innovate and carry the organization forward, because they work with passion and feel deeply connected to the company 
they work for. Disengaged employees are those who do not invest energy and passion in their work, acting tough during the working day. The authors believe that those who are actively disengaged undermine the achievements of their colleagues, because they not only feel unhappy in the workplace, but actively spread this.

Nitin Vazirani also took over Gallup's definitions in 2007. For engaged employees, he used the term "builders" and showed that they are always eager to find out the company's expectations, in order to achieve them and even exceed those expectations. The author believes that disengaged employees focus mainly on tasks and not on the results that are expected from them, and therefore, they have a constant need to be told what to do in order to be able to complete the assigned task. While engaged employees are constantly carrying out their work with high performance, disengaged ones tend to fail in doing so. The author concluded that actively disengaged, or "cave-diggers", are eternally dissatisfied and constantly against everything, spotting the negative side in any opportunity. Bearing in mind that in an organization, employees work together, such attitude can lead to large negative effects on the organization (Vazirani, N., 2007, 4-5). Regarding the topic of employee engagement, Vazirani identifies the main advantages that engaged employees bring to the organization as follows (Vazirani N., 2007, 6):

- $\quad$ They will stay within the company and will be advocates for the company.

- $\quad$ They will be even more motivated and will work better, which will lead to increased profitability.

- They will establish an emotional connection with the organization which will affect their attitude towards the clients, leading to increased client satisfaction.

- $\quad$ They will align with the strategies and objectives of the organization with passion and involvement.

- Through their attitude, they will contribute to increasing the confidence of employees in the organization, creating an energyladen work environment and giving a boost to the development of the organization.

- $\quad$ They will give meaning to the term 'loyalty' and will promote the image of the company.

Truss, C., Soane, E. and Edwards, C., in the report published by CIPD under the name "Working life: Employment attitudes and engagement 2006", considered engagement as the passion for work. They thought of this concept as being very interesting, taking into consideration the fact that it incorporates both people's feelings in relation to their job and their behavior. The authors identified the three components of engagement: emotional engagement in relation to work, cognitive engagement (very strong focus on work and very low deviation of thinking of other problems during work) and physical engagement, which is the tendency to work for the employer even beyond the contractual provisions.

Gankar, S. and Chitale, C. M. (2011, 107-108) highlighted the high level of initiative determined by engagement, considering that engaged employees are willing to do everything within their power for the benefit of the clients and for the success of the organization. Employee engagement is defined by the authors in terms of the extent to which the workforce is engaged, both emotionally and intellectually, for the achievement of the work habits, mission and vision of the organization. Based on these considerations, Gankar, S. and Chitale, C. M. $(2011,108)$ characterized an engaged employee as the one who is strongly involved and enthusiastic about the job and who will act in a way that will exceed the interests of the organization. It may be noted that although in defining employees' engagement, the authors considered only the emotional and intellectual (cognitive) aspects that characterize it, the third aspect is present in defining employees' engagement, namely, the physical aspect.

Susan Sorenson (2013), in the article "How employee engagement drives growth",

Radu MARIN (2021), Journal of Human Resources Management Research,

DOI: $10.5171 / 2021.796417$ 
presented a 2012 Gallup study that reconfirms the already accepted connection between the level of employee engagement and nine outcomes that bring beneficial effects in terms of organisations' performance: customer ratings, profitability, productivity, turnover, safety incidents, level of theft, absenteeism, level of the patient safety incidents and quality, measured by the number of defects.

In the article "Employee Engagement Continues Historic Rise Amid Coronavirus" published on the Gallup website in May 2020, Jim Harter presented the major advantages an engaged employee offers to the organization: producing substantially better results and better attitude towards the client, attracting new clients, increasing the likelihood that he or she will stay within the organization, manifesting a better state of health and decreasing the probability of burnout.

\section{Ways in which organizations can increase the level of employee engagement}

Kahn, W. A. (1990) linked employees engagement with personal engagement, considering engaged employees as the ones who "become physically involved in tasks, whether alone or with others, and are cognitively vigilant and emotionally connected with others, in the service of the work they perform, in ways that display what they think and feel, manifesting their creativity, their beliefs and values and their personal connections with others". The author focused his research on highlighting the psychological conditions that make people feel, from a personal point of view, engaged or disengaged at work. Based on previous studies that had identified the variables that influence the perception of organization's members on themselves and their work, such as their relationship, Kahn tried to demonstrate in his study that both the work and the human experiences are determined by the different degree to which they are willing to use their own psychological qualities, cognitive and emotional, during the job.

The author identifies the psychological conditions that cause people to be involved in the job and to express and use their individuality, or the opposite, which cause them not to use and protect their individuality. The three psychological conditions are: meaningfulness, security and availability. These conditions identified by the author were based on the three fundamental questions that the author assumes that each employees is asking, namely: (1) "How important is it to me to manifest myself within this job?", (2) "How safe is it to do this?", and (3) "How willing am I to do this?".In other words, from a psychological point of view, it is the feeling that employees who receive recognition (as a result of the physical, cognitive and emotional energies invested in their job) have, being determined to feel worthwhile, useful and valuable. Psychological security was defined by the author as: "the willingness of a person to show and employ his individual characteristics, without fearing the negative consequences related to his or her own image, status or career." The researcher defined availability through the prism of the possession of the physical, emotional and mental resources necessary to obtain engagement at a given time.

Kahn, in the study that was considered to be a pioneer in employee engagement, also identified the factors influencing the three psychological conditions as follows: the importance is influenced by task characteristics, role characteristics, and work interactions; security is determined by interpersonal relationships, group and intergroup dynamics, management style and process, and organizational norms; availability is influenced by depletion of physical energy, depletion of emotional energy, individual insecurity, and outside lives. It may be considered that the author has identified personal involvement or lack of personal involvement in the light of the extent to which an employee is willing to manifest his personality, physically, emotionally and mentally, within the job.

Based on the study of Kahn, May, D. R., Gilson, R. L. and Harter, L. M. (2003) conducted a research that aimed to analyze the influence the three psychological conditions (meaningfulness, safety and availability) have on employee engagement. 
The results of the study demonstrated the significantly positive relationship between all three psychological conditions and employee engagement. This type of engagement was called, by the authors, psychological engagement. Moreover, the three forms of engagement identified by Kahn, emotionally, cognitively and physically, were measured by the mediation of 13 elements: four for the cognitive side, four for the emotional side and five for the physical side. The psychological conditions, which were determinative for engagement, were measured as follows: six elements were used for measuring importance, three for measuring safety and five for measuring availability.

The initial model proposed by the authors also measured the factors influencing the three psychological conditions, namely: diversification of work and fit in position, as determinants for meaningfulness; relationship with superiors and team norms, as determinants for security perception of one's own personality in relation to others; personal resources (cognitive, physical and emotional) employed at work and activities outside the organization, as determinants for availability. In the original model proposed by May, D. R., Gilson, R. L. and Harter, L. M., the relationship with colleagues was seen as a determining factor for both importance and security, unlike Kahn's proposed model in which interpersonal relationships were a determining factor for security.

After analyzing the statistical data, the authors concluded the need to improve the model, as follows: job enrichment and work role fit, were maintained as determinants for importance (similar to Kahn's model); superior relations and coworkers norms were maintained as determinants of security, and coworker relations remained a determinant only for security, to which selfconsciousness was added; and for availability, the determinants remained the same; namely resources employed at work and outside activities. In addition, the new model established a direct link between self-consciousness, i.e. personal resources employed in the workplace, and involvement. The latter's connection leads to a significant increase in the importance of the availability of engagement, confirming that for a constant maintenance of resources, the more available the employees are, the more engaged they become, and that, in the case of constant maintenance of availability, the fewer resources the employees have, the more likely they are to be engaged.

Leiter, M. P. \& Maslach, C. $(2008,498)$ analyzed the second construction on which engagement is based, namely burnout. The researchers stated that people have a psychological connection with their jobs, a relationship that can be described as a continuum between negative experiences (burnout) and positive experiences (engagement). This continuum is composed of three dimensions connected to each other: exhaustion-energy, cynicismengagement and inefficiency-efficiency. The authors considered that the existence of this continuum is very important from a practical point of view, because it leads to concluding that measures can be taken to avoid burnout, with the ultimate aim of obtaining employee engagement, for increasing the vigor and energy of employees, to ensure association with work and efficiency in the job.

In a report published in 2003, the consulting firm Towers Perrin considers the definition of employee engagement as being based on both emotional factors (which the authors called "the will") and on rational factors (which they identified as "the way"), manifesting themselves both in relation to the job and the general experience within the workplace. According to the study, emotional factors were related to the satisfaction and sense of accomplishment employees have in their relationship with their jobs and the organization they belong to. Rational factors were associated with the extent to which employees become aware of their role in relation to the organization's objectives. The study highlighted three categories in terms of employee engagement; namely extremely engaged, quite engaged and disengaged.

The author stressed out that, for a total engagement, an employee needs both "the 
will" (adherence to the values of the organization, passion and pride) and "the way" (resources provided by the organization). The study defined the factors that contribute to the increase of employee engagement as follows: a challenging job, customer oriented attitude, career development opportunities, clear vision of senior management regarding the future of the organization (elements related to learning and personal development) and senior management's interest in employees, decision-making authority, the company's reputation as a good employer, collaborative work environment where people work well in teams, resources to complete the assigned tasks, and input on decision making (elements related to the work environment).

It is important to point out that if, in terms of employee attraction and retention, the author identifies four categories of factors that influence employees' decision (financial advantages, benefits, learning and personal development and working environment), only the categories listed above (personal development and working environment) were identified in terms of employee engagement. Also, the study revealed a positive relationship between employee engagement and customer attention (implicitly leading to revenue growth) and a negative relationship between employees' intention to leave the organization and production costs.

Josh Bersin (2015), in the article "Becoming irresistible: A new model for employee engagement", published on Deloitte's website, considers that the employee engagement system in an organization must be based on 20 strategies, also based on five major elements (the importance of the job, the management's implication, the positive working environment, opportunities for growth and trust in leadership), each of these elements being based on four factors , namely: autonomy, employees insert to fit to the job, small and empowered teams, slack time in order to take care of their home lives (for work importance); setting clear and transparent objectives, offering coaching, investments in management development and modern management (for involved management); a flexible working environment, a humanistic job, a recognition based culture and an inclusive and accepting work environment (positive work environment); training and support in the workplace, a facility of talent mobility, self-directed and dynamic learning and a culture of learning with a strong impact (for growth opportunities); mission and purpose, continuous investing in people, transparency and sincerity, and inspiration (leadership trustfulness).

This article was based on the issue presented in the article "Global Human Capital Trends 2014" in which Jeff Schwartz, Josh Bersin and Bill Pelster mentioned that regarding "doing more is not enough", modern organizations have to manage people differently, trying to innovate, transform, and reengineer human resources practices. They identified 12 critical directions for the development of human capital (providing leaders at all levels; redefining learning at organizational level; changing the concept by which employees have rank and yank through coaching and development; the continuous identification of capable workforce, in order to create a global support of qualifications; reviving talent acquisition; building a system that induces passion and purposes; transforming diversity compliance into business strategies; simplifying the working environment; transforming human resources professionals into qualified business consultants; widespread application of talent in practice; integrating talents with human resources and business technologies; and achieving a rapid balance and relocation). According to the authors, these 12 directions could be structured in three clusters: drive and develop, attract and involve, and transform and reinvent.

Following the same path, line Annemarie Mann and Jim Harter, in Gallup's 2016 study "The Worldwide Employ Employment Crisis", ask themselves the following question: "Why doesn't the level of employee engagement increase globally?" The main reason identified by consultants for this situation is that organizations that are exclusively involved in measuring the level of employee involvement fail to take 
measures that could lead to increased engagement, by not focusing on improving employee engagement. This situation arises when the organization sees engagement not as a continuous, disciplined activity, oriented towards achieving a better performance, but as a survey, in which the organization, instead of worrying about the development of employees and managers, focuses more on reports and surveys, and employee engagement is defined in terms of a percentage of employees who are not dissatisfied or are just satisfied with the employer, when in fact, this state should be based on engagement, commitment and enthusiasm.

The authors also believe that organizations, in order to build an active system of employee engagement, should focus on a system of research metrics that highlight the organizational or management problems that stand in the way of engagement and performance. Organizations should also be able to meet employees' expectations as a result of measuring the worker's satisfaction or happiness. The authors concluded that it was necessary to create a culture of engagement that would exceed the annual employee survey, hoping that the managers would change their behavior only based on the analysis of the results of this survey. Organizations, leaders and managers should take into account that any interaction with employees can impact the level of engagement in the organization and its level of performance, which is why special attention must be paid to all elements considered critical from the point of view of engagement.

Lavigna, B. $(2015,733)$ identifies three ways that are available to managers in order to increase employee engagement: to support employees in understanding how their work contributes to the organization's mission, to involve employees in making decisions, and to support their development, so that they contribute to the achievement of the organization's objectives and mission. The author believes that this approach must begin from the hiring moment.
Rebull, M. (2019), considering that, in order to develop employee engagement, it is necessary that employees are intrinsically motivated, takes into account that one way to obtain engagement is to give up on classical methods, to give up on the old organizational culture and to create a new, original and real one. This approach must be based on transparency, valuable leadership, building community, and a relationship based on trust and recognition for a job well done.

A similar opinion is adopted by Albrecht, S. L. $(2010,7)$ who considers that, in order for employees to become engaged, it is necessary to meet the psychological needs related to competence, autonomy and relatedness. The author also mentions the JD-R (Job Demands-Resources) model which explains how engagement is influenced by workplace resources (autonomy, feedback) and personal resources (personal efficiency, optimism, endurance). Engagement influence the work results, such as financial results, results achieved both within the limits of job obligations and beyond these obligations, as well as creativity.

Guaspari, J. (2015) also believes that employee engagement can be achieved through granting responsibilities, trust, respect and values of the organization. Van Tuin, L., Schaufeli, W. B., Van den Broeck, A. and Van Rhenen, W. $(2020,3)$, based on previous studies, identify leadership, work climate and organizational support and work characteristics (variety, challenge, autonomy) as antecedents of employee engagement.

An important factor in increasing employee engagement is employees' perception of the social responsibility of organizations. In this respect, Eisenberger, R., Armeli, S., Rexwinkel, B., Linch, P. D. and Rhoades, L. (2001, 42-43), defining the organizational support perceived as the way in which employees feel affected by the benevolent or malevolent attitude of organizations (politics, norms, actions), determine that employees will modify their behavior according to this perception, by making a decision on the extent to which they will 
contribute to the well-being and achievement of the organization's objectives. The authors believe that employees consider it normal to be treated by the organization in a directly proportional way in terms of the extent to which they are concerned with the wellbeing of the organization, as well as the efforts they are willing to invest in their work.

Colakoglu, U., Culha, O. and Atay, H. (2010, 128), based on previous studies, considered that employees' perception of organizational support, either in the form of human resources attitudes or working conditions, will lead to positive attitudes and behaviors of employees, which will lead them to intensify their efforts so that the organization can achieve its objectives. The study carried out by Mahumbu, D. and Dodd, N. (2013) also identifies a direct correlation between perceived organizational support and employee engagement. Abdelmotaleb, M. (2020) also believes that an organization can influence the positive attitudes of the employees and increase their engagement through the use of social responsibility practices, such as providing training and personal development, a fair work-life balance, care for health and safety.

Taking the same approach into consideration, Cropanzano, R. and Mitchell, M. S. $(2005,876)$ interpreted this relationship through the prism of the theory of social exchange, considering that relationships of mutual involvement, trust and loyalty can develop over time, provided that the parties respect a number of agreed rules. Abukhalifeh, A. and Som, A. (2013) also believed that, based on the theory of social exchange, the reasons why employees decide to be more or less involved can be explained. Thus, the authors considered that the decision of employees to involve their personality more deeply in the activity, and to invest greater efforts cognitively, emotionally and physically, depends on the attitude adopted by the organization.

The authors identify four factors that can help increase employee engagement: more effective communication with employees that allows them to understand their role within the organization; rewards and recognition of their contributions within the organization; and programs that allow employee development and extensive employee care. Regarding this last factor, the authors mentioned that there are three psychological conditions related to the engagement or lack of engagement of employees; namely, the availability, security and importance of work, in the sense that employees will become more engaged and will develop more psychological availability in the workplaces, which will provide them with more security and a deeper feeling of the importance of that work.

\section{Methodology}

The methodology used in this paper is based on analyzing the specialized literature (both academic and practical studies), and it is focused on the literature that covers employee engagement. This research aimed to reveal the big picture of the chosen topic, in order to have a better understanding of unresolved questions and emerging issues, considering that this research can lead to further research and contributions in this area. This study's methodology is an exploratory one and it is considered as being adequate to the purpose of the research.

\section{Discussions}

Employee engagement represents a widely debated topic in the literature (more in that of practitioners and less in the academic one) for three decades. However, to date, no unanimous opinion on this notion has been adopted. In the author's opinion, this is mainly due to the way in which studies on employee engagement have been addressed. As a result of the undertaken analysis, a correct and uniform definition of the term of employee engagement must refer to both the cognitive nature and to the affective and motivational nature that it implies. A complex definition of employee engagement should also refer to the fact that, in order to become engaged, the employee must be aware of the impact that 
his job has on the results of the organization.

It is also considered that a clear distinction must be made between the notion of employee engagement and other related theories (organizational work commitment, organizational citizenship behavior and job involvement), so that employee engagement no longer seems to be an old notion reinvented.

\section{Conclusions}

Based on the statement "doing more is not enough" by Jeff Schwartz, Josh Bersin and Bill Pelster, the author believes that employee engagement is a research topic that will have to be addressed more and more in depth in the coming period, because organizations will face increasing challenges as follows:

1. For the first time in the world's economic history, an organization's workforce is a mix of members belonging to four distinct generations (Baby-Boomers, $\mathrm{X}$ Gen, Millennials and Zoomers), each of which has different expectations and motivational factors. This situation will continue as it is until the end of this decade;

2. In the coming years, Millennials' role in organizations will increase, while the number of Baby-Boomers and X-Gen employees will be in a continuous decline. The Gallup study "State of the American Workplace", published in 2017 (based on data collected between 2015 and 2016), found that, of the three generations, the percentage of Millennials is the lowest (BabyBoomers - 35\%, X-Gen - 33\%, and Millennials - 31\%), with an equal increase of $3 \%$ compared to the 2012 study. The percentage difference does not seem to be very big, however, it must be taken into consideration that, despite the efforts made by the organizations, the same study shows that, in the period 2000-2020, the percentage of engaged employees experienced an increase of only $12 \%$ (from 26\% to $38 \%$ ), the increase in 2020 being considered to be only conjuncture, as shown in this article. Nevertheless, there are two aspects that could make this situation more difficult. On the one hand, it is possible that, as they advance in their careers, Millennials will find the areas of activity and organizations that will fit their expectations, thus increasing their level of engagement. This conclusion is based on the study conducted by Truss, C., Soane, E., Edwards, C., Wisdom, K., Croll, A. and Burnett, J. (2006), which identified a $41 \%$ engaged employees among people over 35 years old, while of the employees under this age, only $26 \%$ were identified as engaged employees. On the other hand, organizations will have to create a style and work environment that meets their expectations, which could lead to an increase in the level of involvement.

3. Women will have an increasingly active role in organizations, and the mentioned Gallup study reveals that the percentage of engaged women is $36 \%$, compared to $30 \%$ recorded by men. On the other hand, however, the same study found that only $35 \%$ of women with a role in leadership are engaged employees, as opposed to men with a role in leadership, for whom, the percentage of those engaged is $50 \%$. It is worth mentioning that the study conducted by Truss, C., Soane, E., Edwards, C., Wisdom, K., Croll, A. and Burnett, J. (2006) mentioned a $37 \%$ engagement rate among women and $30 \%$ among men, which leads to the conclusion that in recent years, the percentage of engagement among women has decreased, while among men has increased.

4. The 2017 study presented a worrying situation related to the percentage of engaged

Radu MARIN (2021), Journal of Human Resources Management Research, 
management, that is, those people who come into direct contact with other employees and would have the necessary power to increase their level of engagement. This percentage was only $29 \%$, i.e. below the general level of engaged employees in the organizations analysed;

5. Despite the current (declared) trend of reducing globalization, this will certainly continue to develop, continuing to bring forward the problems of cultural diversity. Moreover, the process of globalisation could encompass new emerging economies, creating problems related to cultural diversity that large organizations have not yet faced.

\section{Acknowledgment}

There was no external funding.

\section{References}

- Ababneh, O.M.A. (2015) 'The Meaning and Measurement of Employee Engagement: A Review of the Literature', NZJHRM 2015, 15(1), 1-35.

- Abdelmotaleb, M. (2020) 'The moderating and mediating role of public service motivation between organization's social responsibility and employee engagement: evidence from Egyptian public hospitals',International Review of Public Administration, Vol. 25(3), 207-223.

- Abukhalifeh, A.and Som, A. (2013)'The antecedents affecting employee engagement and organizational performance',Asian Social Science, 9(7), 41-46.

- Albrecht, S. L. (2010) Handbook of Employee Engagement. Perspectives, Issues, Research and Practice. Edward Elgar Publishing, Inc., Northampton, Massachusetts.

- Colakoglu, U.,Culha, O.,Atay, H.(2010)'The effects of perceived organisational support on employees' affective outcomes: Evidence from the hotel industry',Tourism and Hospitality Management, 16(2), 125-150.
- Chalofsky, N. E. (2010) Meaningful workplaces, Jossey-Bass, San Francisco, CA.

- Christian, M. S., Garza, A. S. and Slaughter, J. E. (2011) 'Work engagement: a quantitative review and test of its relations with task and contextual performance', Personal Psychology, 64(1). 89-136.

- Cropanzano, R., Mitchell, M.S.(2005)'Social exchange theory: An interdisciplinary review',Journal of Management, Vol. 31, 874-900.

- Das S. P. and Mishra P. S. (2014) 'Antecedents and consequences of employee engagement: a critical analysis of literature review'. International Journal of Human Resources Management (IJHRM), 3(2), 73-86.

- $\quad$ Eisenberger, R., Armeli, S., Rexwinkel, B., Linch, P.D. and Rhoades L. (2001) 'Reciprocation of Perceived Organizational Support',Journal of Applied Psychology, 86(1), 42-51.

- Gallup (2017) State of the American Workplace.

- Gankar, S. and Chitale, C. M. (2011) 'Employee Engagement Key Driver for HR: A Literature Review. Chronicle of The Neville Wadia Institute of Management Studies And Research, April 2011, 107-109.

- Guaspari, J. (2015) Otherwise Engaged. How Leaders Can Get a Firmer Grip on Employee Engagement and Other Key Intangibles , Maven House Press, Palmyra, VA.

- Harter, J. K., Schmidt, F. L. and Hayes, T. L. (2002) 'Business-unit-level relationship between employee satisfaction, employee engagement, and business outcomes: A meta-analysis', Journal of Applied Psychology, 87(2), 268-279.

- Kahn, W. A. (1990) 'Psychological Conditions of Personal Engagement and Disengagement at Work', Academy of Management Journal, 33 (4), 692-724.

- Lavigna, B. (2015) 'Public Service Motivation and Employee Engagement', Public Administration Review • September | October 2015

- Leiter, M. P. and Maslach, C. (2008) 'Early Predictors of Job Burnout and 
Engagement, Journal of Applied Psychology, 93( 3), 498-512.

- $\quad$ Macey, W.H. and Schneider, B. (2008) 'The Meaning of Employee Engagement,,Industrial and Organizational Psychology, 1, 3-30.

- Macey, W.H., Schneider, B., Barbera, K.M. and Young, S.A. (2009) 'Employee Engagement: Tools for Analysis', Practice, and Competitive Advantage. Valtera Corporation.

- MacLeod, D. and Clarke, N. (2009) Engaging for Success: Enhancing Performance Through Employee Engagement, Department for Business, Innovation and Skills, London.

- Mathumbu. D.and Dodd, N. (2013)'Perceived organizational support, work engagement and organizational citizenship behaviour of nurses at Victoria hospital',Journal of Psychology, 4(2), 87-93.

- Rebull, M. (2019) Strategic HR Review, Vol.18(3), 104-108.

- Robinson, D., Perryman, S. and Hayday, S. (2004), 'The drivers of employee engagement'. [Online],[Retrieved January 13,2021], www.employmentstudies.co.uk

- Rothbard, N. P. (2001) 'Enriching or depleting? The dynamics of engagement in work and family roles', Administrative Science Quarterly, 46(4), 655-684.

- Saks, A. M. (2006) 'Antecedents and consequences of employee engagement', Journal of Managerial Psychology, 21(7), 600-619.

- Schaufeli, W., Salanova, M., GonzalezRoma, V. and Bakker, A. B. (2002) 'The measurement of engagement and burnout: A two sample confirmatory factor analytic approach', Journal of Happiness Studies, 3, 71-92.

- Shanmugam, P. and Krishnaveni, R. (2012) 'Employee engagement: an introspection into its conceptualization', International Journal of Social Science \& Interdisciplinary Research, 1(9), 186194.

- Shuck, B., and Wollard, K. (2010) 'Employee engagement and HRD: a seminal review of the foundations'.
Human Resource Development Review, 9(1), 89-110.

- $\quad$ Shuck, M. B., Rocco, T. S. and Albornoz, C. A. (2011) 'Exploring employee engagement from the employee perspective: implications for HRD'. Journal of European Industrial Training, 35(4), 300-325.

- Shuck, B., Reio, T.G. and Rocco, T.S. (2011) 'Employee engagement: an examination of antecedent and outcome variables', Human Resource Development International, 14(4), 427-445.

- Truss, C., Soane, E., Edwards, C., Wisdom, K., Croll, A. and Burnett, J. (2006) Working Life: Employee Attitudes and Engagement 2006, CIPD, London.

- Towers Perrin (2003) Working Today: Understanding What Drives Employee Engagement. The 2003 Towers Perrin Talent Report.

- Van Tuin, L., Schaufeli, W.B., Van den Broeck, A. and van Rhenen, W. (2020) 'A Corporate Purpose as an Antecedent to Employee Motivation and Work Engagement,Frontiers in Psihology, Vol. 11, 1-12.

- Vazirani, N. (2007) 'Employee Engagement', SIES: College of Management Studies Working Paper Series.

- Zigarmi, D., Nimon, K., Houson, D., Witt, D. and Diehl, J. (2009) 'Beyond engagement: toward a framework and operational definition for employee work passion', Human Resource Development Review, 8(3), 300-326.

- Witemeyer, H., Ellen, P. and Straub, D. (2013) 'Validating a Practice-Informed Definition of Employee Engagement', Third Annual International Conference on Engaged Management Scholarship, Atlanta, Georgia. September 19-22, 2013.

\section{Electronic References}

- $\quad$ https://news.gallup.com/business journal/20311/work-feelinggood-matters.aspx

- https://www2.deloitte.com/us/en /insights/deloitte-review/issue-

Radu MARIN (2021), Journal of Human Resources Management Research, DOI: $10.5171 / 2021.796417$ 
16/employee-engagementstrategies.html\#endnote-sup-55

- https://www.gallup.com/workpla ce/311561/employee-

engagement-continues-historicrise-amid-coronavirus.aspx

- https://www.gallup.com/workpla ce/313313/historic-dropemployee-engagement-followsrecord-rise.aspx

- https://www.gallup.com/workpla ce/316064/employee- engagement-hits-new-highhistoric-drop.aspx

- https://www.gallup.com/workpla ce/330017/employeeengagement-rises-following-wild2020.aspx

- https://www.gallup.com/workpla ce/236927/employeeengagement-drives-growth.aspx

- https://www2.deloitte.com/us/en /insights/focus/human-capitaltrends/2014/hc-trends-2014introduction.html 